\title{
Reduced Lipid Pecans: Chemical Alterations and Implications for Quality Maintenance during Storage
}

\author{
Ravindranath V. Kanamangala, Niels O. Maness, ${ }^{1}$ Michael W. Smith, Gerald H. Brusewitz, ${ }^{2}$ \\ Sue Knight, ${ }^{3}$ and Bhaggi Chinta ${ }^{3}$ \\ Department of Horticulture and Landscape Architecture, Oklahoma State University, Stillwater, OK 74078
}

AdDitional INDEX words. Carya illinoinensis, shelf life, hexanal, sensory, rancidity, supercritical carbon dioxide extraction, lipid class

\begin{abstract}
The unextracted and reduced lipid (supercritical carbon dioxide extraction of $22 \%$ and $27 \%$ (w/w) of total lipids) pecan [Carya illinoinensis (Wangenh.) K. Koch] kernels packaged in $21 \% \mathrm{O}_{2}, 79 \% \mathrm{~N}_{2}$ were analyzed for color, hexanal, sensory, fresh weight, and lipid class changes periodically during 37 weeks of storage at $25{ }^{\circ} \mathrm{C}$ and $55 \%$ relative humidity. Pecan nutmeats were lightened by partial lipid extraction. The pecan testa darkened (decreasing chromameter $\left.L^{*}\right)$ with storage time. Most color changes occurred in the first 18 weeks. Hexanal concentration of reduced-lipid pecans was negligible throughout storage, while unextracted pecans reached excessive levels by week 22 of storage. Hexanal concentration, indicative of rancidity, was in agreement with sensory analysis results with the hexanal threshold level for objectionable rancidity ranging from 7 to $11 \mathrm{mg} \cdot \mathrm{kg}^{-1}$ pecans. Weight change was negligible during storage, except in $27 \%$ reduced-lipid pecans. Free fatty acids increased with storage and were significantly higher in unextracted pecans than the reduced-lipid pecans at $0,10,18,32$, and 37 weeks of storage. Shelf life of pecans with partial lipid extraction was longer than unextracted pecans. In addition to decreasing the total amount of lipid available for oxidation, the free fatty acid lipid component that correlated with the development of rancidity was reduced by extraction.
\end{abstract}

Pecans (Carya illinoinensis) are a perishable product that must be refrigerated to preserve quality over extended periods. In practice, however, storage of pecans during retail distribution is often at ambient temperatures, resulting in quality deterioration caused by rancidity and associated off-flavor development. The off-flavors associated with rancidity are caused, to a large extent, by products of oxidative cleavage of polyunsaturated fatty acids (Erickson, 1993). Pecans range from $55 \%$ to $70 \%$ lipid (Worley, 1994), with a high degree of unsaturation for component fatty acids (90\% unsaturated fat, $65 \%$ monounsaturated, and $25 \%$ polyunsaturated; Maness et al., 1995). The major lipid classes found in pecans are triacylglycerols, diacylglycerols, monoacylglycerols, free fatty acids, and phospholipids (Santerre, 1994).

The three major steps in development of rancidity in the pecan appear to be 1) hydrolysis of component glycerides into free fatty acids, 2) oxidation of double bonds of unsaturated fatty acids to form peroxides, with 1 and 2 referred to as induction period, and 3) an autooxidation of the free fatty acid pool, referred to as the autooxidation stage (Kays, 1982). For autooxidation to occur, peroxides must accumulate in sufficient quantities to sustain continued oxidative cleavage. It is during the autooxidation stage that oxidation products such as hexanal accumulate in sufficient quantity to allow sensory perception of rancid flavors (Erickson et al., 1994).

Some of the strategies to improve pecan storage stability include low temperature storage (Simms, 1994), monoglyceride coating

Received for publication 6 June 1998. Accepted for publication 24 Mar. 1999. Approved for publication by the Director, Oklahoma Agricultural Experiment Station. This research was supported by Oklahoma Center for the Advancement of Science and Technology grant AR4-044, U.S. Department of Agriculture grant 9634150-2540, and the Oklahoma Agricultural Experiment Station. The cost of publishing this paper was defrayed in part by the payment of page charges. Under postal regulations, this paper therefore must be hereby marked advertisement solely to indicate this fact.

${ }^{1}$ To whom reprint requests should be addressed.

${ }^{2}$ Department of Biosystems and Agricultural Engineering.

${ }^{3}$ Department of Nutritional Sciences. containing antioxidants (Luce, 1967; Senter and Forbus, 1979; Shea, 1965), opaque packaging materials (Heaton and Shewfelt, 1976), heat treatment (Forbus and Senter, 1976; Senter et al., 1984), and reduced oxygen packaging (Dull and Kays, 1988). Frozen storage is probably the most widely used method for extending pecan shelf life for periods of one or more years. Since pecans sold in retail markets are often held in packages at room temperature, methods to improve shelf life under nonfrozen conditions will result in better product quality for the consumer.

Supercritical $\mathrm{CO}_{2}$ partial lipid extraction seems to be promising in increasing shelf life (Divino et al., 1996) and in decreasing fat content of high lipid foods. Traditionally, organic solvents have been used to extract lipids from foods. With increased consumer concern for food quality and safety, more stringent governmental regulations on acceptable solvents and permissible residues, and increasing energy costs, effective alternative extraction methodologies that comply with both consumer preference and regulatory controls must be used. Supercritical fluid extraction (SFE), using $\mathrm{CO}_{2}$ as the solvent may be a viable alternative for the traditional methods.

Little is known about the mechanisms by which pecan shelf life is extended by partial lipid extraction. A widely supported generalization is that the higher the lipid content of a product (Adnan et al., 1981; Divino et al., 1996) and the higher the percentage of polyunsaturated fatty acids (Senter and Horvat, 1976), the more susceptible it is to oxidative rancidity. Thus, low-lipid products are thought to develop lipid oxidation off-flavors at a slower rate than the full-lipid counterpart. An investigation of the changes in fatty acids of different lipid classes upon aging should enhance our current understanding of rancidity, and further elucidate the mechanism by which partial lipid extraction extends shelf life. Therefore, our objectives were to determine if partial lipid extraction extends shelf life and to study the mechanisms of rancidity retardation in reducedlipid pecans. Changes in rancidity were correlated with changes in fatty acid composition of lipid classes during storage of unextracted and reduced-lipid pecans. 


\section{Materials and Methods}

Pecans and Partial LiPID extraction. Native pecan halves from 1996-97 season that had been frozen $\left(-4^{\circ} \mathrm{C}\right)$ were allowed to warm to room temperature $\left(22\right.$ to $25^{\circ} \mathrm{C}$ ) inside sealed freezer bags. Lipids were partially extracted within 3 months of harvest using a Dionex 703 supercritical fluid extraction unit (Dionex Corp., Sunneyvale, Calif.) with coleman grade $\mathrm{CO}_{2}$ (Air Products and Chemicals, Inc., Allentown, Pa.). Four 50-mL extraction vessels were loaded with $15 \mathrm{~g}$ of pecan halves $(\approx 16$ halves) and extractions conducted at $69 \mathrm{MPa}, 40{ }^{\circ} \mathrm{C}$ for either $20 \mathrm{~min}$ or $8 \mathrm{~h}$. The pressure used (69 MPa) was the highest we could go, and anything lower than this pressure would have taken us a lot longer to extract the amount of lipid we wanted to extract. The temperature $\left(40^{\circ} \mathrm{C}\right)$ used was fairly low to prevent roasting of pecans and inducing different flavors, which would have been difficult to compare roasted with unextracted pecans. Extracted lipid was collected in chilled hexane. After extraction, broken halves were removed manually leaving only sound kernels that were frozen $\left(-20^{\circ} \mathrm{C}\right)$ in airtight freezer bags until a sufficient quantity was extracted for the storage study. Lipid samples from the $20 \mathrm{~min}$ and the $8 \mathrm{~h}$ extractions were individually pooled, blanketed with $\mathrm{N}_{2}$ and frozen for analysis.

Packaging AND STORAge. Thirteen micrometers of saran coated mylar (polyster) laminated to $63.5 \mu$ m polyethylene (The Packaging Group, Woodbridge, Ont., Canada) with water vapor and oxygen transmission rates of $0.25 \mathrm{~g} \cdot \mathrm{m}^{-2} \cdot \mathrm{h}^{-1}$ and $0.38 \mathrm{~mL} \cdot \mathrm{m}^{-2} \cdot \mathrm{h}^{-1}$, respectively, were used for nut storage. Three replications of 20 kernel halves for each extraction level were placed in packages $(\approx 15.2 \times$ $15.2 \mathrm{~cm}$ ) for each storage duration (12 storage times), evacuated from ambient pressure $(98 \mathrm{kPa})$ to $<0.3 \mathrm{kPa}$, back-flushed with a standard air mixture of $21 \%(\mathrm{v} / \mathrm{v}) \mathrm{O}_{2}$ in $\mathrm{N}_{2}$ (Air Products and Chemicals, Chicago, Ill.) to $88 \mathrm{kPa}$, then sealed in a Multivac-A316 vacuum packaging machine (Multivac, Inc., Kansas City, Mo.). The packaged pecans were stored in a controlled environment chamber at $25{ }^{\circ} \mathrm{C}$ and $55 \%$ relative humidity $(\mathrm{RH})$ in the dark. Three replicated samples from each extraction treatment and an unextracted control were removed after $0,2,4,6,8,10,14,18,22,26,32$, and 37 weeks of storage for quality analysis.

Color ANALYSIS. Five pecan halves were randomly selected from each treatment replication and the color measured using a Minolta CR200 Chroma Meter (Minolta Corp., Ramsey, N.J.). Illumination source was a pulsed xenon arc lamp which uses diffuse illumination and $0^{\circ}$ viewing angle. It was calibrated to a standard white plate (calibration plate CR-A43 Minolta Corp., Ramsey, N.J.). Since pecans were smaller than the standard $8 \mathrm{~mm}$ Chroma Meter's aperture, a black disk with a 3-mm hole was secured over the aperture to block out any side light. CIELAB color parameters $L^{*}, a^{*}$ and $b^{*}$ were measured at five points on each pecan half. Two measurements of seed coat (testa) color were taken on the dorsal side and two on the ventral side of the kernel and one measurement of nutmeat color at the point of detachment (POD) where the two cotyledons separated. Color measurements were averaged by site, 10 of dorsal testa color, 10 of ventral testa color, and five of POD nutmeat color per replication. Color parameters were then expressed as $\mathrm{L}^{*}, \mathrm{~h}^{\circ}$, and $\mathrm{C}^{*}$ as indicated by McGuire (1992).

Hexanal analysis. Ten pecan halves from each replicate were ground in a Waring blender (Waring Products Division, New Hartford, Conn.) to a particle size $<1 \mathrm{~mm}$. Six, 0.5-g aliquots from each sample were weighed into $3.7-\mathrm{mL}$ glass vials fitted with Teflon-lined silicone septa caps. A known amount of 4-heptanone was added to each vial as an internal standard before sealing. The samples were then incubated at $90{ }^{\circ} \mathrm{C}$ for $15 \mathrm{~min}$ in a dry-block heater. A 1.0-mL sample of headspace gas was removed from the vial immediately following the incubation period and injected onto a Tracor 540 gas chromatograph (Tracor Instruments, Austin, Texas) equipped with a split injector (split ratio 1:50) and an FID detector. Injector temperature was $275^{\circ} \mathrm{C}$ and detector temperature was $300{ }^{\circ} \mathrm{C}$. Separations were carried out on a DB-23 fused silica capillary column $(30 \mathrm{~m} \times 0.25 \mathrm{~mm}$ i.d., $0.25-\mu \mathrm{m}$ film thickness; $\mathrm{J}$ and W Scientific Inc., Rancho Cardova, Calif.) with helium carrier gas at a linear flow rate of $20 \mathrm{~cm} \cdot \mathrm{s}^{-1}$. Oven temperature was maintained at $50{ }^{\circ} \mathrm{C}$ for $2 \mathrm{~min}$, then increased at $10^{\circ} \mathrm{C} \cdot \mathrm{min}^{-1}$ for 4 min. Peak areas were obtained using a Spectra-Physics 4270 integrator (Spectra-Physics Inc., San Jose, Calif.). Hexanal was identified according to coelution with an authentic standard and quantified relative to 4-heptanone as internal standard. After hexanal analysis, the remaining ground sample was blanketed with $\mathrm{N}_{2}$ and frozen for quantitative lipid extraction later.

Taste Panel EVAluation. The ten remaining kernels from each replication in storage were used for sensory evaluation. Since only 10 kernels were available for sensory evaluation, the sensory panel consisted of only three individuals who were trained for pecan flavor analysis. Kernels were cut into about $3 \mathrm{~mm}^{2}$ pieces and provided to the taste panel. Flavors of samples were evaluated for rancid taste on a numbered scale, with 0 being no detectable rancidity and 5 being very rancid. A score of 3 or above indicated objectionable levels of rancidity.

QUANTITATIVE SUPERCRITICAL $\mathrm{CO}_{2}$ EXTRACTION. The remainder of ground samples from the hexanal analysis were allowed to reach room temperature $\left(22\right.$ to $25^{\circ} \mathrm{C}$ ) before opening and used for quantitative lipid extraction. A Dionex 703 (Dionex Corp., Sunneyvale, Calif.) supercritical fluid extraction instrument was used for quantitative extraction of pecan lipid, essentially as described by Maness et al. (1995). Extractions were carried out simultaneously in eight, $2.5 \mathrm{~mL}$ extraction vessels (two samples replicated four times) at $69 \mathrm{MPa}$ (final pressure) and $75^{\circ} \mathrm{C}$ using 250 $\mathrm{mL} \cdot \mathrm{min}^{-1}$ restrictors for $64 \mathrm{~min}$. At the beginning of each run, a twostage ramp in pressure from 0 to $25 \mathrm{MPa}$ and from 25 to $50 \mathrm{MPa}$, with durations of 2 min each was necessary to prevent restrictor clogging. Restrictors were maintained at $150^{\circ} \mathrm{C}$. The lipid from each extraction vessel was channeled into vials containing $15 \mathrm{~mL}$ of chilled hexane $\left(2^{\circ} \mathrm{C}\right)$. Gaseous $\mathrm{CO}_{2}$ flow rate and total flow were determined from flow meters for each vessel.

Upon completion of extraction, extracts were transferred quantitatively into tared $8 \mathrm{~mL}$ vials using hexane and dried in vacuo with a Speed Vac sample concentrator equipped with an ultralow sample condenser and an organic vapor trap (Savant Inc., Farmingdale, N.Y.). Lipid yields were determined gravimetrically. The lipid was then blanketed with $\mathrm{N}_{2}$ and frozen, to be used for lipid class separation.

LIPID CLASS SEPARATION. The lipid samples from quantitative extractions, and pooled lipid samples previously obtained during partial extractions, were used for lipid class separations after temperature equilibration. Bond Elut aminopropyl bonded phase columns with stainless steel frits (500 mg; Varian, Harbor City, Calif.) were used for separation and isolation of lipid classes. This solid phase separation technique involved creating selectivity in the isolation of compounds by serially altering the mobile phase. The lipid classes can be isolated essentially to homogeneity with $>95 \%$ recovery (Kaluzny et al., 1985). Table 1 lists the solvents used in the Bond Elut isolation of pecan lipid classes.

Before use, the aminopropyl columns were preconditioned twice under vacuum with $2 \mathrm{~mL}$ portions of hexane. Vacuum was released immediately after the second hexane wash to prevent the columns 
Table 1. Solvents used in the Bond Elut isolation and purification of lipid classes.

\begin{tabular}{|c|c|c|c|c|}
\hline Name & Solvent & $\begin{array}{l}\mathrm{Vol}^{\mathrm{z}} \\
(\mathrm{mL})\end{array}$ & $\begin{array}{c}\text { Eluate } \\
\text { no. }\end{array}$ & $\begin{array}{l}\text { Lipids } \\
\text { eluted }\end{array}$ \\
\hline$\overline{\mathrm{A}}$ & Chloroform-2-propanol (2:1) & 4 & 1 & All neutral lipids \\
\hline B & Acetic acid-diethyl ether $(0.2: 9.8)$ & 4 & 2 & Fatty acids \\
\hline $\mathrm{C}$ & Methanol & 4 & 3 & Phospholipid \\
\hline $\mathrm{D}$ & Hexane & 4 & 4 & Cholestrol esters \\
\hline $\mathrm{E}$ & Diethyl ether-methylene chloride-hexane $(0.1: 1: 8.9)$ & 12 & 5 & Triacylglycerols \\
\hline $\mathrm{F}$ & Ethyl acetate in hexane $(0.5: 9.5)$ & 4 & 6 & Cholestrol \\
\hline G & Ethyl acetate-hexane (1.5:8.5) & 4 & 7 & Diacylglycerols \\
\hline $\begin{array}{l}\mathrm{H} \\
\text { Monoa }\end{array}$ & Chloroform-methanol (2:1) & 4 & 8 & \\
\hline
\end{tabular}

${ }^{\mathrm{z} V o l u m e}$ of solvent used to elute the corresponding lipid class.

from becoming completely dry. Lipid samples $(0.5 \mathrm{mg})$ in chloroform $(0.5 \mathrm{~mL})$ were applied to the column and the chloroform allowed to elute at normal atmospheric pressure. Neutral lipids, free fatty acids, and phospholipids were then obtained as noted in Table 1. The neutral lipid fraction was then further fractionated on a new preconditioned column to obtain cholestryl esters, triacylglycerols, cholesterol, diacylglycerols, and monoacylglycerols. As a deviation to the original procedure it was necessary to increase the elution volume of solvent $\mathrm{E}$ (from 6 to $12 \mathrm{~mL}$ ) to accommodate increased amounts of triacylglycerols in pecan lipids, relative to other classes. The elution volume for cholesterol was decreased from 12 to $4 \mathrm{~mL}$ because cholesterol in samples was essentially zero.

Eluates ( 2 to 8 ) were transferred quantitatively into tarred 8-mL vials and dried in vacuo with a speed vac sample concentrator equipped with an ultralow sample condenser and an organic vapor trap (Savant, Inc.). The weight of the eluates (lipid classes) were determined. Lipid classes were then subjected to fatty acid analysis.

Samples of lipid from duplicated storage replications were run three times. Separations were conducted with standard lipids (lipid standard 178-6; Sigma Chemical Co., St. Louis, Mo.), that contained $33.3 \%$ each of monoolein, diolein, and triolein; L- $\alpha$ phosphatidylinositol (P-0639); L- $\alpha$-phosphatidylcholine (P-3556); oleic acid (O-1008); linoleic acid (L-1376); to substantiate results from the original method, and to accommodate optimization of the method for pecan lipid separation.

The lipid class separation procedure was used for two experiments in this study. The objective of the first experiment was to determine if any selectivity for lipid classes occurred as a consequence of partial lipid extraction. Lipids from unextracted pecans obtained during quantitative extraction were compared to pooled lipids obtained during the $20 \mathrm{~min}$ and $8 \mathrm{~h}$ partial lipid extractions, by lipid class separation procedure. No storage treatment was imposed on pecans for the first experiment. Since the partial extracts for 20min and 8-h extractions were pooled together from all pecans extracted, we compared them to the lipids from unextracted pecans separately.

The objective of the second experiment was to determine the mechanism of shelf life extension of reduced-lipid pecans. For this, the quantitatively extracted lipids from unextracted, $22 \%$ reducedlipid (extracted $20 \mathrm{~min}$ ), and $27 \%$ reduced-lipid (extracted $8 \mathrm{~h}$ ) pecans, of storage weeks $0,10,18,22,26,32$, and 37 were subjected to lipid class separation procedure.

FATTY ACID METhYL ESTER PREPARATION AND ANALYSIS. Heptadecanoic acid (HDA), as internal standard, was added to the vials containing the lipid classes. The amount of HDA was adjusted to the weight of the eluates $\left(600 \mathrm{nmol} \cdot \mathrm{mg}^{-1}\right)$. Two-hundred $\mathrm{mL}$ methanolic HCL ( $3 \mathrm{~mol} \cdot \mathrm{L}^{-1} \mathrm{HCL}$ in methanol, prepared by adding
$0.5 \mathrm{~mL}$ acetic anhydride to $10 \mathrm{~mL}$ methanol) and $50 \mathrm{~mL}$ methyl acetate (as a water scavenger) was added and vials were sealed with teflon lined caps and incubated $2 \mathrm{~h}$ at $90^{\circ} \mathrm{C}$ in a dry heating block. It was necessary to mix the vial contents by vortexing during the first $15 \mathrm{~min}$ of the incubation period to assure equilibrium of the eluates into a single phase for methanolysis. Following incubation, vials were cooled and 10 drops of tertiary butanol was added to coevaporate the HCL and the samples were dried under $\mathrm{N}_{2}$ gas. Fatty acid methyl esters were dissolved into hexane, with the volume of hexane based on the fresh weight of the eluate $\left(600 \mathrm{~mL} \cdot \mathrm{mg}^{-1}\right)$. A $1-\mu \mathrm{L}$ aliquot was used for gas chromatography.

Gas chromatography was conducted using a Tracor model 540 gas chromatograph (Tracor Instruments), equipped with a split injection port (split ratio of 50:1) and flame ionization detector. Separations were performed using a DB 23 fused silica capillary column $(30 \mathrm{~m} \times 0.25 \mathrm{~mm}$ i.d., $0.25 \mu \mathrm{m}$ film thickness; J and $\mathrm{W}$ Scientific Inc., Rancho Cardova, Calif.) with helium carrier gas at a linear flow rate of $20 \mathrm{~cm} \cdot \mathrm{s}^{-1}$. Injector temperature was $275^{\circ} \mathrm{C}$ and detector temperature was $300^{\circ} \mathrm{C}$. Initial column temperature was 50 ${ }^{\circ} \mathrm{C}$ for 2 min. Fatty acid methyl esters were then separated using a linear temperature program from 50 to $180^{\circ} \mathrm{C}$ at $10^{\circ} \mathrm{C} \cdot \mathrm{min}^{-1} \mathrm{~min}$, a hold at $180^{\circ} \mathrm{C}$ for $5 \mathrm{~min}$, and a second linear temperature program from 180 to $240{ }^{\circ} \mathrm{C}$ at $5^{\circ} \mathrm{C} \cdot \mathrm{min}^{-1}$ and a hold at $240{ }^{\circ} \mathrm{C}$ for a final 5 min. Individual FAME peaks are identified according to coelution with an authentic standard (FAME preparation 2; Sigma Chemicals Co.). Peak areas were obtained using a Spectra-Physics 4270 integrator (Spectra-Physics Inc., San Jose, Calif.) and quantified relative to HDA as internal standard.

\section{Experimental Design and Statistical Analysis}

SELECTIVITY EXPERIMENT. Fatty acid composition and lipid class quantity of the lipids extracted from pecans during the partial lipid extraction process were compared to lipids obtained by quantitative

Table 2. Mean lipid content, ${ }^{\mathrm{z}}$ lipid reduction, weight per pecan, and weight reduction of unextracted, 20-min extracted, and 8-h extracted pecans.

\begin{tabular}{lcccc}
\hline \hline & $\begin{array}{c}\text { Lipid } \\
\text { content } \\
(\%)\end{array}$ & $\begin{array}{c}\text { Lipid } \\
\text { reduction } \\
(\%)\end{array}$ & $\begin{array}{c}\text { Wt/ } \\
\text { pecan } \\
(\mathrm{g})\end{array}$ & $\begin{array}{c}\mathrm{Wt} \\
\text { reduction } \\
(\%)\end{array}$ \\
\hline None & $64 \pm 2.5^{\mathrm{y}}$ & 0 & $0.86 \pm 0.05^{\mathrm{y}}$ & 0.0 \\
$20 \mathrm{~min}$ & $50 \pm 1.6$ & 22 & $0.69 \pm 0.04$ & 19.8 \\
$8 \mathrm{~h}$ & $47 \pm 1.3$ & 27 & $0.64 \pm 0.04$ & 25.6
\end{tabular}

${ }^{\mathrm{z}}$ All results are a grand mean for all the extractions of all storage durations.

yMean $\pm \mathrm{SE}$. 
Table 3. Weight change (percent of initial) during storage of unextracted, $22 \%$ reduced-lipid, and $27 \%$ reduced-lipid pecans.

\begin{tabular}{lccc}
\hline \hline $\begin{array}{l}\text { Storage } \\
\text { duration }\end{array}$ & \multicolumn{3}{c}{ Wt change $(\%)$} \\
\cline { 2 - 4 } (weeks) & Unextracted & 22\% reduced-lipid & 27\% reduced-lipid \\
\hline 0 & 0.06 & 0.00 & 0.15 \\
2 & -0.11 & 0.09 & 0.45 \\
4 & 0.15 & 0.24 & 1.34 \\
6 & 0.04 & 0.10 & 1.25 \\
8 & 0.15 & -0.27 & 1.69 \\
10 & 0.28 & 0.48 & 1.53 \\
14 & 0.30 & 0.39 & 1.84 \\
18 & 0.28 & 0.23 & 1.84 \\
22 & 0.06 & 0.29 & 1.17 \\
32 & 0.27 & -0.22 & 1.43 \\
37 & 0.04 & -0.13 & 1.16 \\
Mean weight & & & \\
change over & & $0.11 \mathrm{~b}$ & \\
storage & $0.14 \mathrm{~b}^{\mathrm{z}}$ & &
\end{tabular}

$\overline{\mathrm{LSD}_{0.05} \text { for average weight change over storage }=0.19 \text {. Means with the }}$ same letter are not significantly different.

extraction. Extraction times were; 0 min (unextracted), $20 \mathrm{~min}$ (22\% reduced lipid), and 8 h (27\% reduced lipid). Data were analyzed as a completely randomized design with mean separation by LSD.

STORAGE EXPERIMENT. Treatments were a factorial combina- tion of pecan extraction levels (three lipid contents) and storage durations (12 storage times). Means with standard error are presented for lipid content, pecan fresh weight, kernel color parameters, hexanal concentration, and sensory panel evaluation of pecan rancidity. Individual lipid class recoveries and the fatty acid profile of each lipid class were analyzed as a split plot design with pecan lipid content as the main plot and storage duration as the sub plot. If the interaction between lipid content and storage duration was significant, the main effect of storage duration and the interaction of lipid content with storage duration were pooled, then the trends of storage duration by pecan lipid content treatment were calculated (Snedecor and Cochran, 1967). Appropriate LSD values were calculated to compare means for lipid content of pecans. Unless noted otherwise, only results significant at $P=$ 0.05 are discussed.

\section{Results}

Partial and quantitative lipid extraction. Pecans that were extracted for $20 \mathrm{~min}$ or $8 \mathrm{~h}$ lost $22 \%$ and $27 \%$ of total lipids, respectively (Table 2). Percent lipid reduction was arrived at using the formula (total grams lipid of reduced lipid pecan per total grams lipid of unextracted pecan) $\times 100$. Lipid content of unextracted, $20 \mathrm{~min}$, and $8 \mathrm{~h}$ extracted were $64 \%, 50 \%$, and $47 \%$ $(\mathrm{w} / \mathrm{w})$ respectively. There were no differences in lipid yields in these three samples across storage duration, indicating that there was no loss of lipid during storage.

WeIGHT Loss. During storage, pecan fresh weight change was

Table 4. Color parameters ${ }^{\mathrm{z}}$ by site, lipid reduction, and storage time.

\begin{tabular}{|c|c|c|c|c|c|}
\hline \multirow{2}{*}{$\begin{array}{l}\text { Color } \\
\text { parameter }\end{array}$} & \multirow{2}{*}{$\begin{array}{c}\text { Measurement } \\
\text { site }\end{array}$} & \multirow{2}{*}{$\begin{array}{c}\text { Lipid } \\
\text { reduction } \\
(\%)\end{array}$} & \multicolumn{3}{|c|}{$\begin{array}{l}\text { Storage time } \\
\text { (weeks) }\end{array}$} \\
\hline & & & 0 & 18 & 37 \\
\hline \multirow[t]{9}{*}{$\mathrm{L}^{*}$} & Dorsal & 0 & $66.7 \pm 0.5$ & $61.3 \pm 0.2$ & $59.9 \pm 0.7$ \\
\hline & & 22 & $65.4 \pm 0.5$ & $61.0 \pm 0.8$ & $60.5 \pm 0.2$ \\
\hline & & 27 & $67.5 \pm 0.5$ & $61.7 \pm 0.9$ & $59.3 \pm 0.5$ \\
\hline & Ventral & 0 & $62.4 \pm 0.7$ & $58.7 \pm 0.6$ & $56.5 \pm 0.6$ \\
\hline & & 22 & $62.8 \pm 0.9$ & $59.4 \pm 0.3$ & $56.4 \pm 0.4$ \\
\hline & & 27 & $63.2 \pm 0.6$ & $59.1 \pm 0.8$ & $57.3 \pm 0.1$ \\
\hline & POD & 0 & $68.7 \pm 0.2$ & $71.6 \pm 0.8$ & $71.7 \pm 1.4$ \\
\hline & & 22 & $77.0 \pm 2.0$ & $77.7 \pm 0.7$ & $79.7 \pm 0.9$ \\
\hline & & 27 & $81.4 \pm 0.8$ & $78.8 \pm 0.9$ & $80.2 \pm 0.5$ \\
\hline \multirow[t]{9}{*}{$\mathrm{C}^{*}$} & Dorsal & 0 & $19.4 \pm 0.1$ & $17.8 \pm 0.3$ & $17.0 \pm 0.7$ \\
\hline & & 22 & $21.1 \pm 0.8$ & $18.1 \pm 0.8$ & $18.5 \pm 0.4$ \\
\hline & & 27 & $24.0 \pm 0.6$ & $20.1 \pm 0.5$ & $18.2 \pm 0.8$ \\
\hline & Ventral & 0 & $17.8 \pm 0.8$ & $15.4 \pm 0.8$ & $13.9 \pm 0.5$ \\
\hline & & 22 & $19.5 \pm 0.7$ & $16.9 \pm 0.6$ & $14.4 \pm 0.6$ \\
\hline & & 27 & $20.9 \pm 1.0$ & $17.5 \pm 0.6$ & $16.1 \pm 0.1$ \\
\hline & POD & 0 & $11.8 \pm 0.4$ & $11.4 \pm 0.4$ & $12.3 \pm 0.3$ \\
\hline & & 22 & $12.3 \pm 0.8$ & $12.0 \pm 0.1$ & $13.0 \pm 0.2$ \\
\hline & & 27 & $13.5 \pm 0.3$ & $13.0 \pm 0.1$ & $13.7 \pm 0.4$ \\
\hline \multirow[t]{9}{*}{$h^{\circ}$} & Dorsal & 0 & $71.9 \pm 1.3$ & $58.3 \pm 0.9$ & $58.2 \pm 1.2$ \\
\hline & & 22 & $70.2 \pm 0.6$ & $58.7 \pm 0.5$ & $58.9 \pm 0.8$ \\
\hline & & 27 & $69.6 \pm 0.2$ & $55.4 \pm 1.7$ & $53.7 \pm 0.7$ \\
\hline & Ventral & 0 & $71.7 \pm 2.2$ & $57.2 \pm 0.7$ & $55.6 \pm 1.9$ \\
\hline & & 22 & $68.9 \pm 1.0$ & $57.2 \pm 1.1$ & $54.2 \pm 1.0$ \\
\hline & & 27 & $68.4 \pm 0.1$ & $53.7 \pm 1.8$ & $52.5 \pm 1.0$ \\
\hline & POD & 0 & $89.7 \pm 0.4$ & $83.6 \pm 0.7$ & $84.9 \pm 0.9$ \\
\hline & & 22 & $90.8 \pm 0.9$ & $87.3 \pm 0.4$ & $91.0 \pm 0.3$ \\
\hline & & 27 & $91.7 \pm 0.6$ & $87.4 \pm 0.4$ & $89.7 \pm 0.3$ \\
\hline
\end{tabular}

\footnotetext{
$\overline{{ }^{\mathrm{z}} \text { Means }(n=3) \pm \text { SE. }}$
} 


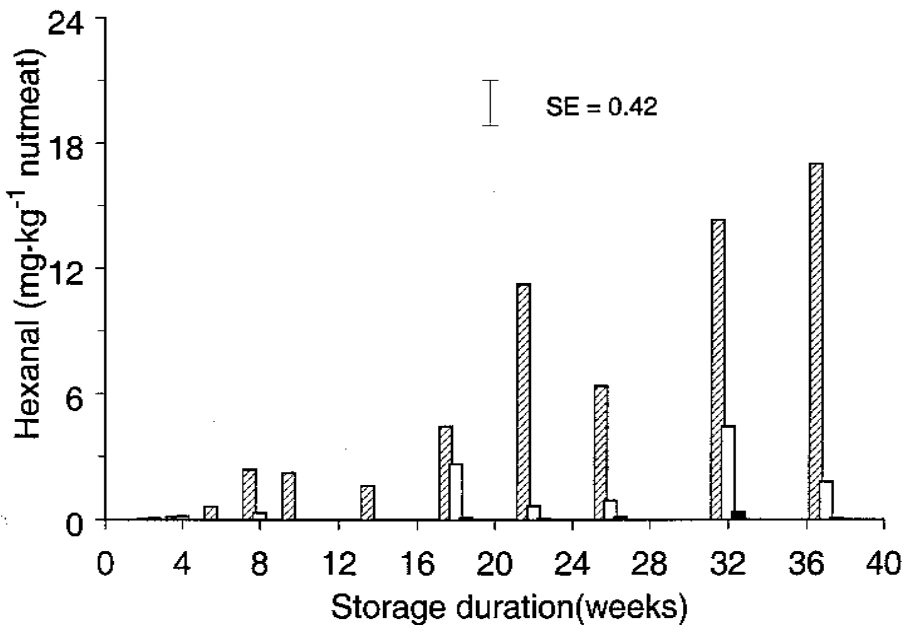

Fig. 1. Hexanal concentration (mg. $\mathrm{kg}^{-1}$ nutmeat) of unextracted (cross-hatched), $22 \%$ reduced-lipid (open) and $27 \%$ reduced-lipid (solid) pecan kernels following storage up to 37 weeks. Values are expressed as the means of three replications. Vertical bar represents the pooled SE of the experimental treatments.

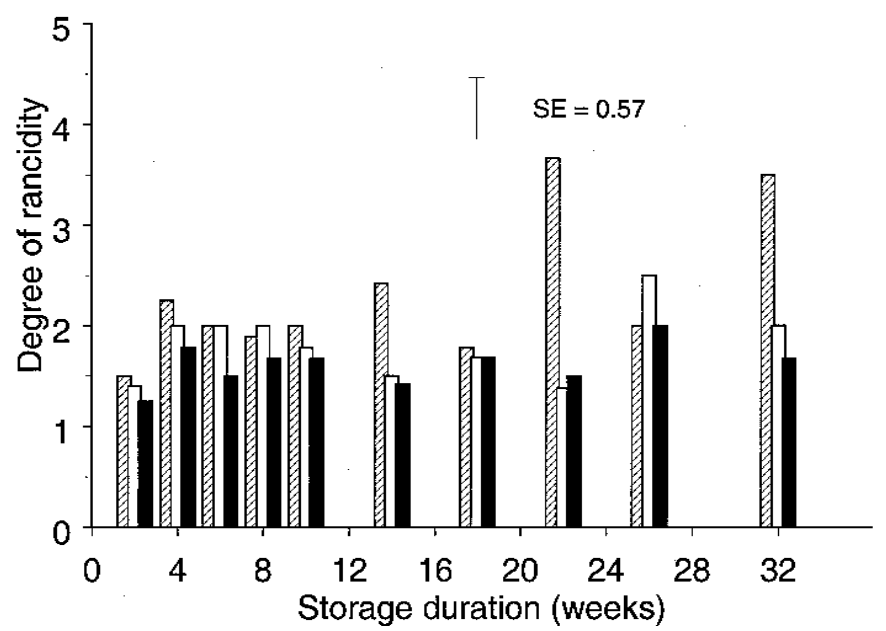

Fig. 2. Sensory panel rancid flavor rankings for unextracted (cross-hatched), $22 \%$ reduced-lipid (open) and 27\% reduced-lipid (solid) pecan kernels following storage up to 37 weeks. Values are expressed as the means of three replications. Vertical bar represents the pooled SE of the experimental treatments.

slight, most of which occurred within the first 4 to 6 weeks (Table $3)$. The $27 \%$ reduced-lipid pecans gained more fresh weight $(1.26 \%)$ than unextracted $(0.14 \%)$ or $22 \%$ reduced-lipid pecans $(0.11 \%)$.

COLOR ANALYSIS. Lipid reduction affected all color parameters, except dorsal L* (Table 4). Ventral and POD L* values increased with lipid reduction, indicating lightened pecan testa and nutmeats. Lipid reduction caused testa color to be more intense (higher $\mathrm{C}^{*}$ ). The POD became whiter. Testa of reducedlipid pecans had lower $h^{\circ}$ values than unextracted pecans, indicating redder color. Storage duration also affected testa color. The pecan testa darkened (decreasing $\mathrm{L}^{*}$ ) at a relatively rapid rate during the first 4 weeks of storage, then continued to darken at a slower, almost linear rate. Pecan testa $\mathrm{C}^{*}$ and $\mathrm{h}^{\circ}$ values decreased during storage (Table 4).

Hexanal analysis. Hexanal production was affected by storage time and lipid extraction (Fig. 1). Hexanal concentration ranged from 0.0 to $17.0 \mathrm{mg} \cdot \mathrm{kg}^{-1}$ nutmeat for unextracted (not extracted) pecans, 0.0 to $4.4 \mathrm{mg} \cdot \mathrm{kg}^{-1}$ nutmeat for $22 \%$ reducedlipid pecans, and 0.0 to $0.6 \mathrm{mg} \cdot \mathrm{kg}^{-1}$ nutmeat for $27 \%$ reducedlipid pecans over the 37 -week storage period. Hexanal values for unextracted pecans were greater than reduced-lipid pecans at weeks 22, 32, and 37. There were no statistical differences between $22 \%$ and $27 \%$ reduced-lipid pecans over the duration of the experiment.

Taste Panel Evaluation. Sensory panel results indicated only marginally detectable (score of 1 ) to mild (score of 2 ) rancid flavor in pecans at all lipid levels until week 22 of storage (Fig. 2). Objectionable levels of rancidity (score of 3 or above) were noted for unextracted pecans in weeks 22 and 32, but were never noted for reduced-lipid pecans. However, the 26 week samples of the unextracted pecans were not judged objectionably rancid by the sensory panel. This agrees with a lower hexanal concentration (Fig. 1) since there was a decline in hexanal concentration at 26 weeks of storage ( $7 \mathrm{mg} \cdot \mathrm{kg}^{-1}$ nutmeat), compared with 22 (11 $\mathrm{mg} \cdot \mathrm{kg}^{-1}$ nutmeat $)$, and $32\left(14 \mathrm{mg} \cdot \mathrm{kg}^{-1}\right.$ nutmeat $)$ weeks of storage. Apparently autooxidation was not initiated to a level which could be detected as objectionably rancid in the 26-week sample. The 37-week samples were not tasted by the panel because it was clear from the odor that they were rancid.

FATTY ACID ANALYSIS OF WHOLE (UNFRACTIONATED) LIPID. Fatty acid analysis of unfractionated lipids indicated they were similar across extraction level and storage duration. The main fatty acids were oleic, linoleic, palmitic, stearic, and linolenic and the grand means of these fatty acids in $\mathrm{mg} \cdot \mathrm{g}^{-1}$ lipid were $659,246,61,22$, and 12 , respectively.

SELECTIVITY EXPERIMENT. Lipid extracted from pecans during partial extraction was compared to the total lipid extracted from pecans by lipid class separation to determine if any selectivity for lipid classes occurred as a consequence of partial lipid extraction (Table 5). Triacylglycerols were the major component, followed by monoacylglycerols, diacylglycerols, and free fatty acids. Phospholipids were a very minor component.

Lipid extracted from pecans during $20 \mathrm{~min}$ and $8 \mathrm{~h}$ partial extraction had a higher free fatty acid content compared with total lipid from the pecans (Table 5). Also lipid extracted from pecan by 20 min partial extraction had more free fatty acids than lipid extracted by $8 \mathrm{~h}$ partial extraction. Palmitic and stearic acids in the lipid obtained during partial extraction were higher than that of the total lipid.

Phospholipid content (mg. $\mathrm{g}^{-1}$ lipid) and composition were not significantly affected by partial lipid extraction. Likewise, triacylglycerol content $\left(\mathrm{mg} \cdot \mathrm{g}^{-1}\right.$ lipid) was also not significant in these comparisons. There was a difference in the triacylglycerol fatty acid composition in many cases. Notable among them was that oleic acid was greater and linoleic acid was lower in the lipid obtained by partial extraction than in the total lipid.

Diacylglycerol and monoacylglycerol content $\left(\mathrm{mg} \cdot \mathrm{g}^{-1}\right.$ lipid $)$ were higher in the lipid extracted from pecan by partial extractions than in the total lipid. Also, oleic and linoleic acids were higher in the lipid extracted from pecans by partial extractions than in the total lipid.

StORAGE EXPERIMENT. Quantitatively extracted lipids from unextracted, $22 \%$, and $27 \%$ reduced-lipid pecans stored for 0,10 , $18,22,26,32$, or 37 weeks were subjected to lipid class separation and fatty acid analysis. To account for the change in relative kernel lipid content between unextracted and reduced-lipid pecans, mole percent values were converted to milligrams per kernel. Before storage, the free fatty acids per pecan were lower in $22 \%$ and $27 \%$ reduced-lipid pecans than in unextracted (not extracted) pecans (Table 6). Free fatty acid increased linearly with storage duration in unextracted pecans, and increased curvilinearly with storage time in $22 \%$ and $27 \%$ reduced-lipid 
Table 5. Comparison of the lipid class recoveries and their fatty acid composition for the total lipid in pecans versus the lipid extracted from pecans by partial extraction process. Means are an average of six runs. ${ }^{\mathrm{z}}$

\begin{tabular}{|c|c|c|c|c|c|c|}
\hline \multirow{2}{*}{$\begin{array}{l}\text { Time } \\
\text { extracted }^{y}\end{array}$} & \multirow{2}{*}{$\begin{array}{c}\text { Recovery } \\
\left(\mathrm{mg} \cdot \mathrm{g}^{-1} \text { lipid }\right)\end{array}$} & \multicolumn{5}{|c|}{ Fatty acid $\left(\mathrm{mg} \cdot \mathrm{g}^{-1}\right.$ lipid $)$} \\
\hline & & Palmitic & Stearic & Oleic & Linoleic & Linolenic \\
\hline & & \multicolumn{5}{|c|}{ Free fatty acids } \\
\hline Total lipid & 4.1 & 1.3 & 1.4 & 1.0 & 0.4 & --- \\
\hline $20 \mathrm{~min}$ & 5.9 & 1.8 & 2.0 & 1.6 & 0.5 & --- \\
\hline $8 \mathrm{~h}$ & 4.8 & 1.8 & 1.9 & 0.8 & 0.4 & --- \\
\hline \multirow[t]{2}{*}{$\mathrm{LSD}_{0.05}$} & 0.5 & 0.3 & 0.4 & 0.4 & NS & --- \\
\hline & & \multicolumn{5}{|c|}{ Phospholipids } \\
\hline Total lipid & 2.0 & 0.9 & 0.9 & 0.1 & --- & --- \\
\hline $20 \mathrm{~min}$ & 2.3 & 1.1 & 1.1 & 0.1 & --- & --- \\
\hline $8 \mathrm{~h}$ & 2.0 & 0.9 & 1.0 & 0.1 & --- & --- \\
\hline \multirow{2}{*}{$\mathrm{LSD}_{0.05}$} & NS & NS & NS & NS & --- & --- \\
\hline & & \multicolumn{5}{|c|}{ Triacylglycerols } \\
\hline Total lipid & 947.2 & 58.1 & 20.1 & 661.9 & 248.8 & 13.6 \\
\hline $20 \mathrm{~min}$ & 941.9 & 51.4 & 16.7 & 561.7 & 216.8 & 9.4 \\
\hline $8 \mathrm{~h}$ & 936.3 & 56.4 & 19.0 & 614.2 & 235.5 & 11.2 \\
\hline \multirow[t]{2}{*}{$\mathrm{LSD}_{0.05}$} & NS & 3.5 & 1.7 & 32.2 & 16.7 & NS \\
\hline & & \multicolumn{5}{|c|}{ Diacylglycerols } \\
\hline Total lipid & 2.9 & 0.4 & 0.2 & 1.6 & 0.7 & --- \\
\hline $20 \mathrm{~min}$ & 4.7 & 0.7 & 0.4 & 2.7 & 0.9 & --- \\
\hline $8 \mathrm{~h}$ & 4.0 & 0.5 & 0.2 & 2.3 & 1.0 & --- \\
\hline \multirow[t]{2}{*}{$\mathrm{LSD}_{0.05}$} & 1.1 & NS & NS & 0.5 & 0.2 & --- \\
\hline & & \multicolumn{5}{|c|}{ Monoacylglycerols } \\
\hline Total lipid & 9.5 & 1.1 & 0.6 & 4.4 & 3.4 & --- \\
\hline $20 \mathrm{~min}$ & 17.8 & 2.3 & 1.4 & 8.7 & 5.3 & --- \\
\hline $8 \mathrm{~h}$ & 13.0 & 1.6 & 0.9 & 5.5 & 5.0 & --- \\
\hline $\mathrm{LSD}_{0.05}$ & 2.6 & 0.6 & NS & 1.3 & 1.0 & --- \\
\hline
\end{tabular}

${ }^{\mathrm{z}}$ Recoveries obtained by aminopropyl column separations as described in materials and methods.

${ }^{\mathrm{y}}$ Comparison between total lipids (from unextracted pecans) versus lipids obtained during the 20 min and $8 \mathrm{~h}$ partial extraction.

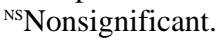

pecans. The free fatty acid pool in unextracted pecans was $>22 \%$ reduced-lipid pecans at 10,32 , and 37 weeks of storage and was $>27 \%$ reduced-lipid pecans at 10,18, 22, 32, and 37 weeks of storage.

Phospholipid content in the reduced-lipid pecans were lower than the unextracted pecans throughout the storage study (Table 6 ). Phospholipids in unextracted and $27 \%$ reduced-lipid pecans decreased with storage time but the changes were not significant in the $22 \%$ reduced-lipid pecans.

Triacylglycerol content in the unextracted pecans were erratic during storage (Table 6). There was a slight increase in triacylglycerols in the $22 \%$ reduced-lipid pecans, but in the $27 \%$ reduced-lipid pecans triacylglycerols were stable.

Diacylglycerols in all three extraction levels increased quadratically with storage. There was no significant difference between the three extraction levels for any storage duration (Table 6). In contrast to diacylglycerols, monoacylglycerols decreased with storage in all three extraction treatments (Table 6) but there was no significant difference between the three extraction levels.

The main fatty acids in free fatty acid fraction were stearic, palmitic, oleic, and linoleic. Free fatty acid in unextracted pecans had more saturated fatty acids (palmitic and stearic) than the reduced-lipid pecans throughout storage (Table 7). Both palmitic acid and stearic acid increased in unextracted pecans during storage. In $22 \%$ and $27 \%$ reduced-lipid pecans, no significant trend with storage duration was observed for palmitic and stearic acids. Before storage, oleic and linoleic acids were lower in the reduced-lipid pecans than the unextracted pecans. Oleic acid content during weeks 18 and 22 was greater in $22 \%$ reduced-lipid pecans than unextracted pecans (Table 7). With storage, oleic acid increased linearly in unextracted pecans, and increased curvilinearly in $22 \%$ and $27 \%$ reduced-lipid pecans. Linoleic acid in unextracted, $22 \%$ reduced-lipid and $27 \%$ reduced-lipid pecans increased quadratically with storage.

The main fatty acids in the phospholipid fraction were palmitic and stearic acids (Table 8). Both palmitic and stearic acids were lower in reduced-lipid pecans than unextracted pecans throughout storage. Changes with storage time were frequently statistically significant, but were small.

Palmitic, stearic, oleic, linoleic, and linoleic acids were the main fatty acids in the triacylglycerol fraction. These fatty acids were lower in the reduced-lipid pecans than unextracted pecans throughout storage (Table 9).

Composition of diacylglycerols changed during storage. All the fatty acids (oleic, linoleic, palmitic, and stearic) increased with storage, particularly in the first 10 weeks (Table 10). There was no significant difference in any of the four acids between the three extraction levels during storage.

The main fatty acids in monoacylglycerols were also oleic, linoleic, palmitic, and stearic. In contrast to diacylglycerols, all the fatty acids in monoacylglycerol decreased with storage in all three extraction levels (Table 11). Most of the changes in fatty acid content occurred during the first 18 weeks of storage, with relatively small changes thereafter; $22 \%$ and $27 \%$ reduced-lipid pecans had a lower oleic concentration than unextracted pecans at weeks 10 and 18. 
Table 6. Lipid class recoveries ( $\mathrm{mg} / \mathrm{kernel}$ ) for lipids from unextracted, $22 \%$ reduced-lipid, and $27 \%$ reduced-lipid pecans as affected by storage duration. Means are averages of six runs. $^{\mathrm{z}}$

\begin{tabular}{lccc}
\hline \hline $\begin{array}{l}\text { Storage } \\
\text { duration }\end{array}$ & \multicolumn{1}{c}{$\begin{array}{c}\text { Recovery } \\
\left(\mathrm{mg} / \text { kernel }^{\mathrm{y}}\right)\end{array}$} \\
\cline { 2 - 4 } (weeks) & Unextracted & $22 \%$ reduced lipid & $27 \%$ reduced lipid \\
\hline
\end{tabular}

\begin{tabular}{lccc}
\hline & Free fatty acids \\
0 & 2.12 & 1.33 & 1.30 \\
10 & 2.51 & 2.05 & 2.00 \\
18 & 2.94 & 2.42 & 2.04 \\
22 & 2.96 & 2.64 & 2.35 \\
26 & 2.50 & 2.10 & 1.92 \\
32 & 3.35 & 2.68 & 2.57 \\
37 & 2.98 & 2.51 & 2.12 \\
Linear & $* *$ & $* *$ & $*$ \\
Quadratic & NS & $* *$ & $* *$ \\
Cubic & NS & NS & $*$
\end{tabular}

$\mathrm{LSD}_{0.05}$ (for same storage week $)^{\mathrm{x}}=0.44$

$\begin{array}{lccc} & \text { Phospholipids } \\ 0 & 1.00 & 0.63 & 0.57 \\ 10 & 0.95 & 0.60 & 0.59 \\ 18 & 0.84 & 0.57 & 0.52 \\ 22 & 0.81 & 0.67 & 0.56 \\ 26 & 0.81 & 0.65 & 0.52 \\ 32 & 0.96 & 0.60 & 0.46 \\ 37 & 0.93 & 0.63 & 0.47 \\ \text { Linear } & \text { NS } & \text { NS } & * \\ \text { Quadratic } & * * & \text { NS } & \text { NS } \\ \text { Cubic } & \text { NS } & \text { NS } & \text { NS }\end{array}$

$\mathrm{LSD}_{0.05}$ (for same storage week) ${ }^{\mathrm{x}}=0.13$

$\begin{array}{lcc}0 & 518.0 & \text { Triacylglycerols } \\ 10 & 481.4 & 333.8 \\ 18 & 507.1 & 322.0 \\ 22 & 497.8 & 346.8 \\ 26 & 496.2 & 333.3 \\ 32 & 511.5 & 331.3 \\ 37 & 502.2 & 348.7 \\ \text { Linear } & \text { NS } & 341.2 \\ \text { Quadratic } & * & * \\ \text { Cubic } & * * & \text { NS }\end{array}$

$\mathrm{LSD}_{0.05}$ (for same storage week $)^{\mathrm{x}}=14.3$

$\begin{array}{lc}0 & 1.50 \\ 10 & 5.72 \\ 18 & 4.82 \\ 22 & 6.97 \\ 26 & 8.01 \\ 32 & 7.67 \\ 37 & 5.92 \\ \text { Linear } & * * \\ \text { Quadratic } & * * \\ \text { Cubic } & \text { NS }\end{array}$

\section{Diacylglycerols}

$\begin{array}{cc}1.18 & 0.91 \\ 5.64 & 4.72 \\ 5.53 & 6.07 \\ 5.70 & 5.72 \\ 6.68 & 5.82 \\ 6.14 & 5.90 \\ 6.81 & 6.17 \\ * * & * \\ * * & * * \\ \text { NS } & \text { NS }\end{array}$

$\mathrm{LSD}_{0.05}\left(\right.$ for same storage week) ${ }^{\mathrm{x}}=2.2$

$\begin{array}{lc}0 & 4.93 \\ 10 & 5.70 \\ 18 & 4.12 \\ 22 & 1.61 \\ 26 & 1.10 \\ 32 & 1.54 \\ 37 & 1.08 \\ \text { Linear } & * \\ \text { Quadratic } & * * \\ \text { Cubic } & \text { NS }\end{array}$

LSD $_{0.05}$ (for same storage week $)^{\mathrm{x}}=2.1$

$\begin{array}{cc}\text { Monoacylglycerols } & \\ 4.88 & 4.05 \\ 3.64 & 3.69 \\ 2.26 & 2.53 \\ 2.68 & 1.36 \\ 2.69 & 1.50 \\ 1.45 & 1.41 \\ 0.46 & 0.50 \\ * * & \text { NS } \\ * & * * \\ \text { NS } & \text { NS }\end{array}$

${ }^{\mathrm{z}}$ Recoveries obtained by aminopropyl column separations as described in materials and methods.

yMilligrams of representative fatty acids per kernel obtained by fatty acid analysis using gas chromatography, as described in material and methods.

xPairwise comparisons between lipid levels at a particular storage week.

Ns, ${ }^{* * * *}$ Nonsignificant or significant at $P \leq 0.05$ or 0.01 , respectively.
Table 7. Fatty acid profile of free fatty acid lipid class ( $\mathrm{mg} / \mathrm{kernel})$ for lipids from unextracted, $22 \%$ reduced-lipid, and $27 \%$ reduced-lipid pecans as affected by storage duration. Means are averages of six runs. ${ }^{\mathrm{z}}$

\begin{tabular}{lccc}
\hline $\begin{array}{l}\text { Storage } \\
\text { duration }\end{array}$ & \multicolumn{3}{c}{$\begin{array}{c}\text { Profile } \\
\left(\mathrm{mg} / \text { kernel }^{\mathrm{y}}\right)\end{array}$} \\
\cline { 2 - 4 } (weeks) & Unextracted & $22 \%$ reduced lipid & $27 \%$ reduced lipid \\
\hline & & Palmitic acid & \\
0 & 0.66 & 0.51 & 0.50 \\
10 & 0.74 & 0.57 & 0.60 \\
18 & 0.87 & 0.65 & 0.49 \\
22 & 0.83 & 0.61 & 0.52 \\
26 & 0.75 & 0.57 & 0.52 \\
32 & 0.91 & 0.63 & 0.58 \\
37 & 0.82 & 0.60 & 0.51 \\
Linear & $* *$ & NS & NS \\
Quadratic & NS & NS & NS \\
Cubic & NS & NS & NS
\end{tabular}

$\operatorname{LSD}_{0.05}(\text { for same storage week })^{\mathrm{x}}=0.10$

\begin{tabular}{lccc} 
& \multicolumn{3}{c}{ Stearic acid } \\
0 & 0.75 & 0.52 & 0.56 \\
10 & 0.90 & 0.64 & 0.64 \\
18 & 0.93 & 0.61 & 0.45 \\
22 & 0.88 & 0.68 & 0.52 \\
26 & 0.80 & 0.54 & 0.55 \\
32 & 1.09 & 0.63 & 0.57 \\
37 & 1.12 & 0.61 & 0.52 \\
Linear & $* *$ & NS & NS \\
Quadratic & $*$ & NS & NS \\
Cubic & $* *$ & NS & NS
\end{tabular}

$\mathrm{LSD}_{0.05}(\text { for same storage week })^{\mathrm{x}}=0.11$

$\begin{array}{lccc}0 & 0.51 & 0.19 & 0.17 \\ 10 & 0.49 & 0.55 & 0.81 \\ 18 & 0.70 & 1.07 & 0.71 \\ 22 & 0.66 & 1.07 & 0.70 \\ 26 & 0.57 & 0.62 & 0.77 \\ 32 & 0.91 & 0.81 & 0.89 \\ 37 & 0.67 & 0.82 & 0.73 \\ \text { Linear } & * & \text { NS } & * * \\ \text { Quadratic } & \text { NS } & * * & * \\ \text { Cubic } & \text { NS } & * & \text { NS }\end{array}$

$\mathrm{LSD}_{0.05}(\text { for same storage week })^{\mathrm{x}}=0.24$

$\begin{array}{cc}\text { Linoleic acid } & \\ 0.11 & 0.07 \\ 0.39 & 0.51 \\ 0.59 & 0.39 \\ 0.49 & 0.35 \\ 0.38 & 0.45 \\ 0.60 & 0.53 \\ 0.48 & 0.36 \\ * * & * * \\ * * & * \\ \text { NS } & \text { NS }\end{array}$

$\mathrm{LSD}_{0.05}(\text { for same storage week })^{\mathrm{x}}=0.13$

$\overline{{ }^{2} \text { Recoveries obtained by aminopropyl column separations as described in materials and }}$ methods.

${ }^{\mathrm{y}}$ Milligrams of representative fatty acids per kernel obtained by fatty acid analysis using gas chromatography, as described in material and methods.

${ }^{x}$ Pairwise comparisons between lipid levels at a particular storage week.

Ns,*,** Nonsignificant or significant at $P \leq 0.05$ or 0.01 , respectively.

\section{Discussion}

The partial lipid extraction process caused minimum kernel breakage and lightened pecan nutmeats (Table 4). Flavor of the partially extracted pecans was less intense, probably because the lipid contained most of the flavor (Woodroof, 1983).

The small amount of fresh weight gain during storage of $27 \%$ reduced-lipid pecans (Table 3) was probably due to moisture uptake. The $27 \%$ reduced-lipid pecans had less lipid, and likely had 
Table 8 . Fatty acid profile of phospholipid lipid class ( $\mathrm{mg} / \mathrm{kernel}$ ) for lipids from unextracted, $22 \%$ reduced-lipid, and $27 \%$ reduced-lipid pecans as affected by storage duration. Means are averages of six runs. ${ }^{\mathrm{z}}$

\begin{tabular}{|c|c|c|c|}
\hline \multirow{2}{*}{$\begin{array}{l}\text { Storage } \\
\text { duration } \\
\text { (weeks) }\end{array}$} & \multicolumn{3}{|c|}{$\begin{array}{c}\text { Profile } \\
\left(\mathrm{mg} / \text { kernel }^{\mathrm{y}}\right)\end{array}$} \\
\hline & Unextracted & $22 \%$ reduced lipid & $27 \%$ reduced lipid \\
\hline \multicolumn{4}{|c|}{ Palmitic acid } \\
\hline 0 & 0.45 & 0.31 & 0.25 \\
\hline 10 & 0.44 & 0.30 & 0.27 \\
\hline 18 & 0.39 & 0.26 & 0.26 \\
\hline 22 & 0.39 & 0.32 & 0.29 \\
\hline 26 & 0.40 & 0.33 & 0.23 \\
\hline 32 & 0.40 & 0.27 & 0.18 \\
\hline 37 & 0.40 & 0.27 & 0.23 \\
\hline Linear & $*$ & NS & $*$ \\
\hline Quadratic & NS & $*$ & NS \\
\hline Cubic & NS & NS & NS \\
\hline \multicolumn{4}{|c|}{$\mathrm{LSD}_{0.05}(\text { for same storage week })^{\mathrm{x}}=0.05$} \\
\hline & & Stearic acid & \\
\hline 0 & 0.49 & 0.29 & 0.30 \\
\hline 10 & 0.51 & 0.30 & 0.32 \\
\hline 18 & 0.42 & 0.26 & 0.26 \\
\hline 22 & 0.42 & 0.29 & 0.27 \\
\hline 26 & 0.41 & 0.32 & 0.25 \\
\hline 32 & 0.46 & 0.29 & 0.25 \\
\hline 37 & 0.50 & 0.28 & 0.22 \\
\hline Linear & NS & NS & $* *$ \\
\hline Quadratic & $*$ & NS & NS \\
\hline Cubic & $*$ & NS & NS \\
\hline
\end{tabular}

${ }^{\mathrm{z}}$ Recoveries obtained by aminopropyl column separations as described in materials and methods.

${ }^{y}$ Milligrams of representative fatty acids per kernel obtained by fatty acid analysis using gas chromatography, as described in material and methods.

${ }^{x}$ Pairwise comparisons between lipid levels at a particular storage week.

ss, ${ }^{*}, * *$ Nonsignificant or significant at $P \leq 0.05$ or 0.01 , respectively.

a higher equilibrium moisture content. Water uptake probably explained the greater weight gain by the $27 \%$ reduced-lipid pecans than unextracted and $22 \%$ reduced-lipid pecans.

Pecan shelf life was extended with partial lipid extraction. Hexanal is a direct oxidative breakdown product of linoleic acid, and contributes to the off-flavor associated with rancidity. Resistance of lipids to oxidation, indicated by the time required for the onset of sustained hexanal production, was increased from 6 weeks for unextracted pecans to 18 weeks for $22 \%$ and to 22 weeks for $27 \%$ reduced-lipid pecans (Fig. 1). Also, at 22 weeks hexanal levels in the unextracted pecans rose above $6 \mathrm{mg} \cdot \mathrm{kg}^{-1}$ nutmeat, determined by Hofland et al. (1995) to be undesirably high in sensory analyses. At no time during 37 weeks of storage were $22 \%$ and $27 \%$ reducedlipid pecan hexanal levels above the $6 \mathrm{mg} \cdot \mathrm{kg}^{-1}$ nutmeat. Even though the sensory panel was very small $(n=3)$ due to the limited sample size, the sensory results followed very closely the hexanal results, even in week 26 where reduced hexanal concentration (Fig. 1) was paralleled with reduced sensory perception of rancidity (Fig. 2). These findings tend to reinforce the conclusion that hexanal analysis is an appropriate chemical test for detection of rancid flavors in pecans. For pecans, the hexanal threshold necessary for sensory detection of objectionable rancidity appeared to be between $7 \mathrm{mg} \cdot \mathrm{kg}^{-1}$ nutmeat (26 weeks) and $11 \mathrm{mg} \cdot \mathrm{kg}^{-1}$ nutmeat (22 week). This is slightly above threshold levels reported by Hofland et al. (1995).

Decreased autooxidation as a result of partial lipid extraction from peanuts has been reported, and the explanation given was "decreasing the lipid content would result in less substrate available for attack and less free radical formation" (Adnam et al., 1981;
Table 9. Fatty acid profile of triacylglycerol lipid class ( $\mathrm{mg} / \mathrm{kernel}$ ) for lipids from unextracted, $22 \%$ reduced-lipid, and $27 \%$ reduced-lipid pecans as affected by storage duration. Means are averages of six runs. ${ }^{\mathrm{z}}$

\begin{tabular}{lccc}
\hline $\begin{array}{l}\text { Storage } \\
\text { duration }\end{array}$ & \multicolumn{3}{c}{$\begin{array}{c}\text { Profile } \\
\left(\mathrm{mg} / \text { kernel }^{\mathrm{y}}\right)\end{array}$} \\
\cline { 2 - 4 } (weeks) & Unextracted & $22 \%$ reduced lipid & $27 \%$ reduced lipid \\
\hline & & Palmitic acid & \\
0 & 30.03 & 18.43 & 16.44 \\
10 & 27.84 & 18.50 & 16.94 \\
18 & 27.30 & 19.83 & 15.90 \\
22 & 28.00 & 19.50 & 17.01 \\
26 & 29.93 & 19.10 & 16.76 \\
32 & 30.66 & 19.61 & 16.79 \\
37 & 27.87 & 19.80 & 16.56 \\
Linear & NS & $*$ & NS \\
Quadratic & $*$ & NS & NS \\
Cubic & $* *$ & NS & NS
\end{tabular}

$\mathrm{LSD}_{0.05}(\text { for same storage week })^{\mathrm{x}}=1.3$

$\begin{array}{lcc}0 & 10.36 & \text { Stearic acid } \\ 10 & 7.78 & 6.94 \\ 18 & 8.11 & 5.32 \\ 22 & 8.07 & 7.26 \\ 26 & 10.17 & 6.93 \\ 32 & 12.12 & 5.58 \\ 37 & 11.45 & 7.83 \\ \text { Linear } & * * & 7.69 \\ \text { Quadratic } & * * & * * \\ \text { Cubic } & * * & * *\end{array}$

5.20

5.61

5.25

5.81

6.56

6.82

6.95

**

NS

NS

$\mathrm{LSD}_{0.05}$ (for same storage week) ${ }^{\mathrm{x}}=0.92$

$\begin{array}{lc}0 & 341.96 \\ 10 & 326.38 \\ 18 & 347.08 \\ 22 & 316.16 \\ 26 & 330.63 \\ 32 & 351.99 \\ 37 & 336.73 \\ \text { Linear } & \text { NS } \\ \text { Quadratic } & * * \\ \text { Cubic } & \text { NS }\end{array}$

$\mathrm{LSD}_{0.05}(\text { for same storage week })^{\mathrm{x}}=10.1$

Oleic acid

$228.23 \quad 185.41$

$223.68 \quad 199.39$

$239.12 \quad 195.30$

$220.98 \quad 199.81$

$228.17 \quad 194.30$

$219.92 \quad 202.09$

$229.99 \quad 193.21$

NS

NS

NS

NS

NS

$\begin{array}{lccc} & & \text { Linoleic acid } & \\ 10 & 128.54 & 76.54 & 78.05 \\ 18 & 114.47 & 71.01 & 68.94 \\ 22 & 118.65 & 76.88 & 69.33 \\ 26 & 119.42 & 81.75 & 62.95 \\ 32 & 119.93 & 75.25 & 71.57 \\ 37 & 110.52 & 78.50 & 75.82 \\ \text { Linear } & 110.47 & 79.31 & 61.06 \\ \text { Quadratic } & \text { NS } & * & * \\ \text { Cubic } & * & \text { NS } & \text { NS } \\ & \text { NS } & \text { NS } & \text { NS }\end{array}$

$\mathrm{LSD}_{0.05}(\text { for same storage week })^{\mathrm{x}}=8.8$

\begin{tabular}{lccc}
0 & \multicolumn{3}{c}{ Linolenic acid } \\
10 & 7.02 & 3.67 & 3.82 \\
18 & 4.98 & 3.39 & 3.19 \\
22 & 5.75 & 3.58 & 3.47 \\
26 & 6.39 & 4.07 & 2.54 \\
32 & 5.54 & 3.26 & 3.87 \\
37 & 6.50 & 5.15 & 4.48 \\
Linear & 5.61 & 4.27 & 3.34 \\
Quadratic & NS & $* *$ & NS \\
Cubic & $*$ & $*$ & $*$ \\
\end{tabular}

$\mathrm{LSD}_{0.05}(\text { for same storage week })^{\mathrm{x}}=0.66$

${ }^{\mathrm{z}}$ Recoveries obtained by aminopropyl column separations as described in materials and methods.

${ }^{\mathrm{y}}$ Milligrams of representative fatty acids per kernel obtained by fatty acid analysis using gas chromatography, as described in material and methods.

${ }^{x}$ Pairwise comparisons between lipid levels at a particular storage week.

Ns, ${ }^{* * *}$ Nonsignificant or significant at $P \leq 0.05$ or 0.01 , respectively. 
Table 10. Fatty acid profile of diacylglycerol lipid class ( $\mathrm{mg} / \mathrm{kernel})$ for lipids from unextracted, $22 \%$ reduced-lipid, and $27 \%$ reduced-lipid pecans as affected by storage duration. Means are averages of six runs. $^{\mathrm{z}}$

\begin{tabular}{lccc}
\hline \hline $\begin{array}{l}\text { Storage } \\
\text { duration } \\
\text { (weeks) }\end{array}$ & \multicolumn{3}{c}{$\begin{array}{c}\text { Profile } \\
\left(\mathrm{mg} / \text { kernel }^{\mathrm{y}}\right)\end{array}$} \\
\cline { 2 - 4 } 0 & Unextracted & $22 \%$ reduced lipid & 27\% reduced lipid \\
\hline \multicolumn{3}{c}{ Palmitic acid } \\
10 & 0.22 & 0.19 & 0.13 \\
18 & 0.53 & 0.57 & 0.44 \\
22 & 0.49 & 0.50 & 0.58 \\
26 & 0.67 & 0.32 & 0.58 \\
32 & 0.77 & 0.40 & 0.51 \\
37 & 0.72 & 0.61 & 0.37 \\
Linear & 0.73 & 0.73 & 0.63 \\
Quadratic & $* *$ & $* *$ & $* *$ \\
Cubic & $\mathrm{NS}$ & $\mathrm{NS}$ & $*$ \\
\end{tabular}

$\mathrm{LSD}_{0.05}\left(\right.$ for same storage week) ${ }^{\mathrm{x}}=0.21$

$\begin{array}{lcc} & & \text { Stearic acid } \\ 0 & 0.11 & 0.09 \\ 10 & 0.25 & 0.23 \\ 18 & 0.24 & 0.26 \\ 22 & 0.32 & 0.13 \\ 26 & 0.39 & 0.18 \\ 32 & 0.47 & 0.35 \\ 37 & 0.50 & 0.44 \\ \text { Linear } & * * & * * \\ \text { Quadratic } & \text { NS } & \text { NS } \\ \text { Cubic } & \text { NS } & * *\end{array}$

$\mathrm{LSD}_{0.05}\left(\right.$ for same storage week) ${ }^{\mathrm{x}}=0.13$

\begin{tabular}{lccc}
0 & \multicolumn{3}{c}{ Oleic acid } \\
10 & 0.83 & 0.67 & 0.50 \\
18 & 3.04 & 3.10 & 2.63 \\
22 & 2.71 & 3.18 & 3.39 \\
26 & 3.78 & 3.22 & 3.23 \\
32 & 4.38 & 3.05 & 3.18 \\
37 & 4.32 & 3.20 & 3.50 \\
Linear & 2.97 & 3.59 & 4.00 \\
Quadratic & $* *$ & $* *$ & $*$ \\
Cubic & $* *$ & $*$ & $* *$ \\
\end{tabular}

$\mathrm{LSD}_{0.05}(\text { for same storage week })^{\mathrm{x}}=1.2$

$\begin{array}{lcc} & \text { Linoleic acid } \\ 0 & 0.33 & 0.25 \\ 10 & 1.91 & 1.74 \\ 18 & 1.39 & 1.59 \\ 22 & 2.21 & 1.39 \\ 26 & 2.48 & 1.01 \\ 32 & 2.18 & 1.98 \\ 37 & 1.93 & 2.05 \\ \text { Linear } & * * & * * \\ \text { Quadratic } & * & * \\ \text { Cubic } & \mathrm{NS} & \mathrm{NS}\end{array}$

$\mathrm{LSD}_{0.05}$ (for same storage week) ${ }^{\mathrm{x}}=0.74$

\footnotetext{
$\overline{{ }^{\mathrm{z}} \text { Recoveries obtained by aminopropyl column separations as described }}$ in materials and methods.

yMilligrams of representative fatty acids per kernel obtained by fatty acid analysis using gas chromatography, as described in material and methods.

xPairwise comparisons between lipid levels at a particular storage week. Ns,*,** Nonsignificant or significant at $P \leq 0.05$ or 0.01 , respectively.
}

Table 11. Fatty acid profile of monoacylglycerol lipid class ( $\mathrm{mg} / \mathrm{kernel})$ for lipids from unextracted, $22 \%$ reduced-lipid, and $27 \%$ reducedlipid pecans as affected by storage duration. Means are averages of six runs. $^{\mathrm{Z}}$

\begin{tabular}{lccc}
\hline \hline $\begin{array}{l}\text { Storage } \\
\text { duration } \\
\text { (weeks) }\end{array}$ & \multicolumn{3}{c}{$\begin{array}{c}\text { Profile } \\
\left(\mathrm{mg} / \text { kernel }^{\mathrm{y}}\right)\end{array}$} \\
\cline { 2 - 4 } 0 & Unextracted & 22\% reduced lipid & 27\% reduced lipid \\
\hline \multicolumn{3}{c}{ Palmitic acid } \\
10 & 0.59 & 0.59 & 0.54 \\
18 & 0.73 & 0.37 & 0.24 \\
22 & 0.52 & 0.29 & 0.22 \\
26 & 0.29 & 0.31 & 0.24 \\
32 & 0.30 & 0.29 & 0.16 \\
37 & 0.31 & 0.31 & 0.21 \\
Linear & 0.34 & 0.22 & 0.15 \\
Quadratic & $* *$ & NS & NS \\
Cubic & $* *$ & NS & NS
\end{tabular}

$\mathrm{LSD}_{0.05}(\text { for same storage week })^{\mathrm{x}}=0.21$

\begin{tabular}{lccc} 
& \multicolumn{3}{c}{ Stearic acid } \\
0 & 0.32 & 0.36 & 0.34 \\
10 & 0.34 & 0.14 & 0.10 \\
18 & 0.30 & 0.14 & 0.09 \\
22 & 0.13 & 0.18 & 0.08 \\
26 & 0.17 & 0.17 & 0.12 \\
32 & 0.14 & 0.16 & 0.10 \\
37 & 0.11 & 0.13 & 0.10 \\
Linear & $*$ & $\mathrm{NS}$ & $\mathrm{NS}$ \\
Quadratic & $\mathrm{NS}$ & $\mathrm{NS}$ & $* *$ \\
Cubic & $* *$ & $* *$ & $* *$
\end{tabular}

$\mathrm{LSD}_{0.05}\left(\right.$ for same storage week) ${ }^{\mathrm{x}}=0.14$

$\begin{array}{lccc}0 & 2.27 & 2.04 & 1.77 \\ 10 & 2.26 & 0.71 & 0.81 \\ 18 & 2.11 & 0.78 & 0.65 \\ 22 & 0.73 & 0.81 & 0.21 \\ 26 & 0.42 & 0.85 & 0.18 \\ 32 & 0.61 & 0.61 & 0.12 \\ 37 & 0.85 & 0.09 & 0.17 \\ \text { Linear } & * * & * & \text { NS } \\ \text { Quadratic } & * & * * & * * \\ \text { Cubic } & \text { NS } & \text { NS } & \text { NS }\end{array}$

$\operatorname{LSD}_{0.05}(\text { for same storage week })^{\mathrm{x}}=1.1$

$\begin{array}{lccc} & & \text { Linoleic acid } & \\ 0 & 1.75 & 1.90 & 1.4 \\ 10 & 1.17 & 0.96 & 0.55 \\ 18 & 1.19 & 0.56 & 0.17 \\ 22 & 0.46 & 0.47 & 0.13 \\ 26 & 0.21 & 0.27 & 0.14 \\ 32 & 0.38 & 0.37 & 0.32 \\ 37 & 0.47 & 0.03 & 0.07 \\ \text { Linear } & * * & * & \text { NS } \\ \text { Quadratic } & * & * * & * * \\ \text { Cubic } & \text { NS } & \text { NS } & \text { NS }\end{array}$

$\mathrm{LSD}_{0.05}\left(\right.$ for same storage week) ${ }^{\mathrm{x}}=0.67$

$\overline{\mathrm{z}}$ Recoveries obtained by aminopropyl column separations as described in materials and methods.

${ }^{\mathrm{y}}$ Milligrams of representative fatty acids per kernel obtained by fatty acid analysis using gas chromatography, as described in material and methods.

${ }^{x}$ Pairwise comparisons between lipid levels at a particular storage week. Ns,*,** Nonsignificant or significant at $P \leq 0.05$ or 0.01 , respectively. 
Divino, et al., 1996). We correlated the changes in the lipid classes during pecan storage with development of rancidity in an attempt to examine the mechanism of rancidity development. Free fatty acids increased during storage, as noted by Erickson (1993) and Forbus and Senter (1976), and are believed to contribute to oxidative instability of many products. Before storage, the lower free fatty acid levels (Table 6) in reduced-lipid pecans, was because free fatty acids were more readily extracted during the partial lipid extraction. Higher free fatty acid levels in the lipid from partial extractions (Table 5), compared with the lipid from total pecan extraction indicated some selectivity for extraction of free fatty acids during partial lipid extraction. Free fatty acids, because of their lower molecular weight, tend to be more soluble in carbon dioxide (Friedrich and Pryde, 1984) than the other lipid classes. The reduced-lipid pecans began storage with a lower free fatty acid content than the unextracted pecans. Consequently, autooxidation was delayed by reduction in substrate for continued peroxide formation. At no time in storage did the free fatty acid levels in reduced-lipid pecans exceed $2.7 \mathrm{mg}$ perkernel, while the unextracted pecans had a maximum free fatty acid level of $3.4 \mathrm{mg}$ per kernel.

In contrast to the earlier findings (Erickson, 1993), the free fatty acids were more highly saturated than unsaturated (Table 7). These differences may arise from the different lipid extraction procedures ( 2 chloroform : 1 methanol vs SFE) as well as different lipid class separation procedures (thin layer chromatography vs aminopropyl bonded phase columns) employed in these two studies.

Phospholipids decreased in the unextracted pecans during storage (Table 6). In pecans, phospholipids have been found to contain more unsaturated fatty acids, which has led other investigators to conclude that deterioration of phospholipid contributes to rancidity development (Erickson, 1993). Our results show that phospholipids mainly had saturated fatty acids with little or no unsaturated fatty acids (Table 8). The discrepancies could be because the extracted phospholipids, which are less soluble in carbon dioxide (Dunford and Temelli, 1995), were not representative of the total phospholipid pool in pecan kernels.

Triacylglycerol content in total pecan lipids (Table 4) corresponded closely to that reported by Senter and Horvat (1976). Losses of linoleic in the triacylglycerol fraction of unextracted pecans occurred during storage, but it did not coincide with increased hexanal concentrations. The inability to correlate losses of polyunsaturated fatty acids with increases in peroxide value during the same time period has been observed by Adnan et al. (1981) in reconstituted partially defatted peanuts.

There is potential to extend the shelf life of pecans by the supercritical carbon dioxide partial lipid extraction process. It has long been the custom to associate deterioration in lipids and fats with a high free fatty acid content (Robertson et al., 1984, 1985), and the free fatty acid value has been very widely used to infer loss of quality. Both the total amount of lipid available for oxidation that could replenish the free fatty acid pool and the free fatty acid pool itself was reduced with supercritical carbon dioxide partial lipid extraction. A possible mechanism for rancidity retardation in pecans as a consequence of partial lipid extraction appears to be an effect of free fatty acid reduction. Total lipid content was also reduced, further decreasing the fatty acids available for replenishment of the free fatty acid pool. It is also possible that the extraction process altered the internal integrity of pecans in some way, thus making the critical lipids less susceptible to attack by oxygen. These results could be crucial in exploring alternate methods via partial lipid extraction for extending shelf life for high lipid products besides pecans.

\section{Literature Cited}

Adnan, M., C.J. Argoudelis, E. Rodda, and J. Tobias. 1981. Lipid oxidative stability of reconstituted partially defatted peanuts. Peanut Sci. 8:13-15.

Divino, G.L., P.E. Koehler, and C.C. Akoh. 1996. Enzymatic and autoxidation of defatted peanuts. J. Food Sci. 61:112-115.

Dull, G.G. and S.J. Kays. 1988. Quality and mechanical stability of pecan kernels with different packaging protocols. J. Food Sci. 53:565-567.

Dunford, N.T. and F. Temelli. 1995. Extraction of phospholipids from canola with supercritical carbon dioxide and ethanol. J. Amer. Lipid Chem. Soc. 72:1009-1015.

Erickson, M.C. 1993. Contribution of phospholipids to headspace volatiles during storage of pecans. J. Food Qual. 16:13-24.

Erickson, M.C., C.R. Santerre, and M.E. Malingre. 1994. Oxidative stability in raw and roasted pecans: Chemical, physical and sensory measurements. J. Food Sci. 59:1234-1238.

Forbus, Jr., W.R and S.D. Senter. 1976. Conditioning pecans with steam to improve shelling efficiency and storage stability. J. Food Sci. 41:794798.

Friedrich, J.P. and E.H. Pryde. 1984. Supercritical $\mathrm{CO}_{2}$ extraction of lipid bearing materials and characterization of the products. J. Amer. Lipid Chem. Soc. 61:223-228.

Heaton, E.K. and A.L. Shewfelt. 1976. Pecan quality: Effect of light exposure on kernel color and flavor. Lebensm. Wiss.u. Technol. 9:201-206.

Hofland, C., Z. Vickers, and C.W. Fritsch. 1995. Sunflower kernel shelf life study: Effects of temperature, package, and roasting lipid on storage flavor. Annu. Mtg. Inst. Food Technol., Anaheim, Calif., 3-7 June.

Kaluzny, M.A., L.A. Duncan, M.V. Merritt, and D.E. Epps. 1985. Rapid separation of lipid classes in high yield and purity using bonded phase columns. J. Lipid Res. 26:135-140.

Kays, S.J. 1982. Storage of pecan kernels under wholesale and retail conditions, p. 367-382. In: D.G. Richardson and M. Meheriuk (eds.). Controlled atmosphere for storage and transport of perishable agricultural commodities, Timber Press, Beaverton, Ore.

Luce, G.T. 1967. Acetylated monoacylglycerols as coatings for selected foods. Food Technol. 21:48-49, 52, 54.

Maness, N.O., D. Chrz, T. Pierce, and G.H. Brusewitz. 1995. Quantitative extraction of pecan lipid from small samples using supercritical carbon dioxide. J. Amer. Lipid Chem. Soc. 72:665-669.

McGuire, R.G. 1992. Reporting of objective color measurements. HortScience 27:1254-1255.

Robertson, J.A., G.W. Chapman, R.L. Wilson, Jr., and R.B. Russell. 1984. Effect of moisture content of lipid type sunflower seeds on fungal growth and seed quality during storage. J. Amer. Lipid Chem. Soc. 61:768-771.

Robertson, J.A., R.J. Roberts, and J.W. Chapman, Jr. 1985. Changes in lipid type sunflower seed stored at $20 \mathrm{C}$ at three moisture levels. J. Amer. Lipid Chem. Soc. 62:1335-1339.

Santerre, C.R. 1994. Pecan composition, p. 98-110. In: C.R. Santerre (ed.). Pecan technology. Chapman and Hall, New York.

Senter, S.D. and W.R. Forbus, Jr. 1979. Effects of acetylated monoacylglycerol coatings on pecan kernel shelf life. J. Food Sci. 44:1752-1755.

Senter, S.D., W.R. Forbus, Jr., S.O. Nelson, R.L. Wilson, Jr., and R.J. Horvat. 1984. Effects of dielectric and steam heating treatments of the storage stability of pecan kernels. J. Food Sci. 49:893-895.

Senter, S.D. and R.J. Horvat. 1976. Lipids of pecan nutmeats. J. Food Sci. 41:1201-1203.

Shea, R. 1965. New edible protective coatings keep nuts fresh. Food Processing 26:148-150.

Simms, K.A. 1994. Mechanization of post-harvest pecan processing, p. 68-86. In: C.R. Santerre (ed.). Pecan technology, Chapman and Hall, New York.

Snedecor, G.W. and W.G. Cochran. 1967. Statistical methods. 6thed. Iowa State Univ. Press, Ames.

Woodroof, J.G. 1983. Peanut butter, p. 181-227. In: J.Woodroof (ed.). Peanut production, processing, products. 3rd ed. AVI Publishing, Westport, Conn.

Worley, R.E. 1994. Pecan physiology and composition, p. 39-48. In: C.R. Santerre (ed.). Pecan technology. Chapman and Hall, New York,. 